\title{
Reliability Estimation of Transport Means Elements Under the Action of Cyclic Loads and Corrosive Environment
}

\author{
P. V. Popovych, V. O. Dzyura* and O. S. Shevchuk \\ Ternopil Ivan Pul'uj National Technical University, \\ Department of Transporting Technology and Mechanics, Ruska st. 56, 46001 Ternopil, \\ Ukraine \\ *E-mail: volodymyrdzyura@ gmail.com
}

\begin{abstract}
The approach for determining the residual life of the vehicles' thin-walled metal elements with cracks under the action of cyclic loads and corrosive environment is developed based on the first law of thermodynamics and the fracture mechanics principles. Based on the results of the mathematical description of electrochemical reactions and separate data of fracture mechanics, the equation describing the kinetics of the corrosion-fatigue cracks propagation is deduced. This equation and the initial and final conditions are a mathematical model for determining the residual life of structural elements. The correctness of the developed analytical models is confirmed by the experimental data known in the literature. The performance of this model is demonstrated on the example of determining the residual life of a plate made of $17 \mathrm{G} 1 \mathrm{~S}$ steel. The plate was diluted by a crack in a $3 \%$ $\mathrm{NaCl}$ solution and subjected to cyclic loading. An increase in the initial size of corrosionfatigue cracks is significant to reduce the period of their subcritical growth.
\end{abstract}

Keywords: Residual life; corrosive environment; stress intensity factor; thin-walled elements; corrosion-fatigue cracks.

\section{INTRODUCTION}

Nowadays, up to $65 \%$ of the mechanisms of transport means elements are known to get out of order under the influence of aggressive (corrosive) environment and mechanical stresses; up to $25 \%$ of these mechanisms are broken down due to the overloads caused by strength losses because of corrosion damages [1-5, 6-14]. According to the data on agrarian production development in Ukraine, the growth of the transportation volumes of chemical and mineral fertilizers [15] is about $2 \%$ of all cargoes. To maintain the tendency, it is rational to take into account the influence of these overaggressive environments on the vehicles' metal materials [16-18]. The performance of 47 semitrailers MM3 -771, 15 semitrailers MM3 -771Б, 13 trailers MM3-768, 7 trailers MM3 -768Б were studies during the period of one calendar year. The mentioned vehicles were engaged in the transportation of mineral and organic fertilizers. The mean time between failures of the main elements of the specified trailers is found to be from 0 to 4000 hours. The insufficient service life of thin-walled metal structures of the undercarriages and suspensions is ascertained.

The percentage of failures ranges from $50 \%$ to $80 \%$ [1-3]. The most characteristic failures of the undercarriages are the cracks in frames, spar and cross bars [1-3]. The analysis of the reasons due to which steel structures enter the failure state became it possible to draw a conclusion on the causal complex of events that lead to failure. In general, the steel structure failures are caused by the defects of manufacturing (stage of 
production), as well as the errors in the designs (stage of designing). The total percentage of failures caused by the inadequate level of design and production quality can reach $60 \%$ $[5,15,19-21]$. The cause analysis of fragile fracture of welded metal structures explains the influence of individual factors in terms of the frequency of their occurrence in emergency states. In total, the number of factors associated with the stresses concentration and cracks propagation reaches up to $50 \%[5,15,19-20]$. The impact of aggressive environment greatly reduces the lifetime of structural elements $[6,9,10]$. The pitting and / or ulcers occur in the locations of damage to the surfaces of metal structures. The corrosive fatigue cracks arise up to critical dimensions, limiting the vehicle's reliability $[1,6,8,9$, 10]. When accelerating the development of cracks [1, 8], the aggressive environments cause a significant reduction in the durability of machine elements.

To calculate the durability of thin-walled vehicle elements, it is necessary to consider the influence of aggressive working environment on the corrosion-fatigue destruction $[1,7,9,10,11]$. Delayed spontaneous fracture of structural elements under the action of variable in time (cyclic) loads and corrosive-aggressive environments is relatively continuous but dangerous process because of the low degree of its predictability and diagnosis. Corrosive environments increase the failure probability of metal materials [1-5] during cyclic loading and cause the propagation of corrosion-fatigue cracks. To determine the service life of vehicles constructions elements under the influence of cyclic loads and corrosive environments, the appropriate analytical models should be applied. Most of the known [4-5, 15, 19-32] mathematical models are based on the analysis of exclusively specific experimental data. Therefore, based on such theories, the service life of only certain elements of structures made of the same materials can be defined.

\section{MATERIALS AND METHODS}

Let us consider an element of metal construction of a vehicle - a plate located in a corrosive environment, weakened by an initial rectilinear crack of length $2 l_{0}$. The crack is stretched by evenly distributed forces $p$, directed perpendicularly to the line of the crack location. The forces are changed cyclically in time (loading the plate with a crack in the Griffiths problem, Figure 1). The number of load cycles $N=N_{*}$ should be determined. After reaching this number, the corrosion-fatigue crack acquires a critical value and the thin-walled element breaks down.

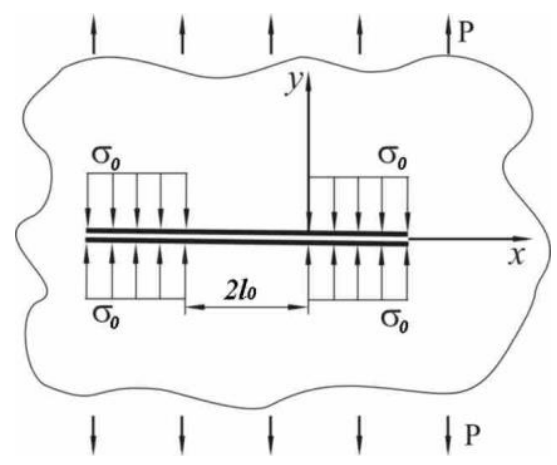

Figure 1. Classical load diagram of the plate with a crack.

To solve this problem, it is necessary to design an analytical model for determining the kinetics of corrosion-fatigue crack propagation and to deduce a differential equation describing the process. The assumption: the stress-strain state in the plate is 
symmetrical to the location line of the crack that extends along the line of location. Similarly [24-26, 29-32], to develop the kinetic equation for the corrosion-fatigue crack propagation, an energy approach based on the first law of thermodynamics is applied for the case of elemental propagation of the crack by the value $\Delta l_{c}$ in time $\Delta t$.

$$
A=W+\Gamma+Q+K
$$

here $A$ - work of external forces; $W$ - energy of body deformation after the crack is increased by the value $\Delta l_{c}$

$$
W=W_{s}+W_{p}^{(1)}(l)+W_{p}^{(2)}(t)-W_{p}^{(3)}(t)
$$

where $\mathrm{W}_{\mathrm{s}}$ - elastic component $\mathrm{W} ; \mathrm{W}_{\mathrm{p}}^{(1)}(\mathrm{l})$ - part of the work of plastic deformations in the pre-fracture area, which depends exclusively on the length of the crack $l ; W_{p}^{(2)}(t)-$ part of the work of plastic deformations caused by external forces, which is performed at a constant crack area during the incubation period of its leap preparation $\Delta \mathrm{l}_{\mathrm{c}}$, and depends only on the time $\mathrm{t}$ (the number of load cycles $\mathrm{N}=\mathrm{tT}^{-1}, \mathrm{~T}$ - the cycle period); $\mathrm{W}_{\mathrm{p}}^{(3)}(\mathrm{t})$ - work of plastic deformations during body unloading and compression of the pre-fracture zone, which depends exclusively on $t$ and is generated by the body itself; $\Gamma$ - body destruction energy depending on 1 , the characteristics of the environment, and $t$; $Q$ - thermal energy released during the fracture of the body, the energy is considered relatively small and is neglected in calculations; $\mathrm{K}$ - kinetic energy, which in this case is also a small value.

According to $[7,10,13]$, the length of the elemental jump of the crack $\Delta \mathrm{l}_{\mathrm{c}}$ is the sum of the mechanical jump $\mathrm{l}_{\mathrm{m}}$ caused by mechanical loading and flooding during electrochemical corrosion and elemental crack propagation $1_{\mathrm{a}}$ due to the anode dissolution.

$$
\Delta l_{c}=l_{m}+l_{a}
$$

Applying [10, 13, 14, 15, 21-24]

$$
l_{m}=\beta\left(\delta_{t}-\xi\right), l_{a}=F m^{-1} n^{-1} \int_{0}^{\Delta t} i(t) d t
$$

where $F$ - Faraday number; $m$ - gram-equivalent weight of metal; $n$ - valence of metal; $\xi, \beta, A$ - experimentally determined constants $[19,21]$.

Since the condition of the energy balance (1) is satisfied, the condition of the velocities balance of the energies components changes is satisfied as well; in time analogy of the load cycles number, $\mathrm{N}$, this condition can be written as Eq. (5)

$$
\partial A / \partial N=\partial W / \partial N+\partial \Gamma / \partial N
$$

Substituting (2) in (5), the specified condition is written

$$
\frac{\partial}{\partial l}\left[\Gamma-\left(A-W_{s}-W_{p}^{(1)}-W_{p}^{(2)}\right)\right] \frac{d l}{d N}+\frac{\partial \Gamma}{\partial N}-\frac{\partial W_{p}^{(3)}}{\partial N}=0 .
$$

Based on Eq. (6), the rate value of crack propagation $V=\partial l / \partial N$ 
$\frac{d l}{d N}=\left[\frac{\partial W_{p}^{(3)}}{\partial N}-\frac{\partial \Gamma}{\partial N}\right] / \frac{\partial}{\partial l}\left[\Gamma-\left(A-W_{s}-W_{p}^{(l)}\right)\right]$

Based on the results [19, 25-29], the expression in square brackets on the right-side Eq. (7) will be written

$$
\partial\left[\Gamma-\left(A-W_{s}-W_{p}^{(1)}-W_{p}^{(2)}\right)\right] / \partial l=\gamma_{C}-\gamma_{t}
$$

where [21, 25-26] $\Gamma=\Delta l_{C} \sigma_{0} \delta_{C C} ; \Gamma=\Delta l_{C} \sigma_{0} \delta_{C C}$ - specific work of plastic deformations in the pre-fracture zone near the top of the crack, $\gamma_{C}=\delta_{C C} \sigma_{0}$ critical value of specific work, $\delta_{C C}=\delta_{C}-A C_{H}(\Delta t)$. Substituting Eq. (8) in Eq. (7), the following formula is deduced

$$
d l / d N=\left[\partial W_{p}^{(3)} / \partial N-\partial \Gamma / \partial N\right] / \sigma_{0}\left(\delta_{C C^{-}} \delta_{t}\right)
$$

Based on [12-15, 19-20] and relations from Eq. (3) and Eq. (4), the values $\partial \mathrm{W}_{\mathrm{p}}^{(3)} / \partial \mathrm{N}, \partial \Gamma / \partial \mathrm{N}$ are determined.

$$
\begin{aligned}
& \partial W_{p}^{(3)} / \partial N=\beta \sigma_{0}\left[\left(\delta_{t \max }-\delta_{t \min }\right)^{2}-\left(\delta_{s c c}^{(\max )}-\delta_{s c c}^{(\min )}\right)^{2}\right], \eta_{2}=0,25 \beta A B \sqrt[4]{T i_{\max }}, \\
& \partial \Gamma / \partial N=-\eta_{2} \sigma_{0} T\left(\delta_{t \max }-\delta_{s c c}^{(\max )}\right)+\sigma_{0} F T n^{-1} m^{-1} i(T)\left[\delta_{C}-A C_{H}(T)\right]
\end{aligned}
$$

where $\delta_{t \max }, \delta_{t \min }, \delta_{s c c}^{(\max )}, \delta_{s c c}^{(\min )}$ - respectively, the maximum and minimum values of the opening at the top of the crack during the load change per cycle [21, 24-29]. Equation (9) is written down based on Eq. (10).

$$
d l / d N=\left\{\beta\left[\left(\delta_{t_{\max }}-\delta_{t_{\min }}\right)^{2}-\left(\delta_{s c c}^{(\max )}-\delta_{s c c}^{(\min )}\right)^{2}\right]+\eta_{2}\left(\delta_{t \max }-\delta_{s c c}^{(\max )}\right)\right\}\left(\delta_{C C}-\delta_{t_{\max }}\right)^{-1}
$$

The case of a macroscopic crack is considered when the following relations are valid [19, 24-26]

$$
\delta_{t}(l) \delta_{C C}^{-1}=K_{I}^{2}(l) K_{I C}^{2}, \quad \delta_{s c c}=K_{s c c}^{2} \sigma_{0}^{-1} E^{-1}, \delta_{t}(l)=K_{I}^{2}(l) \sigma_{0}^{-1} E^{-1}
$$

For this case, Eq. (11) is written

$$
\begin{aligned}
& d l / d N=\left\{\beta_{1}(1-R)^{4}\left(K_{I \text { max }}^{4}-K_{s c c \text { max }}^{4}\right)+\eta_{2}\left(K_{I \text { max }}^{2}-K_{s c c \text { max }}^{2}\right)\right\}\left(K_{f C}^{2}-K_{I \text { max }}^{2}\right)^{-1}, \\
& \beta_{1}=0,25 \beta E^{-1} \sigma_{0}^{-1}
\end{aligned}
$$

where $K_{\text {Imax }}$ is the the maximum value of the stress intensity factor (CIF) per cycle; $K_{f C}, K_{\text {sccmax }}$ are the upper and lower thresholds of CIF on the kinetic diagrams of the fatigue and corrosion-mechanical cracks propagation respectively, $R=K_{\text {Imin }} / K_{\text {Imax }}$ is the asymmetry coefficient of a load cycle [19, 24-27]. To complete the mathematical model, the following initial and final conditions are added to Eq. (13).

$N=0, l(0)=l_{0} ; N=N_{*}, l\left(N_{*}\right)=l_{*} ; K_{I}\left(l_{*}\right)=K_{I C}$. 


\section{RESULTS AND DISCUSSION}

The research results of $17 \mathrm{G} 1 \mathrm{~S}$ steel (Figure 2) [27, 30], studied in air and in 3\% solution $\mathrm{NaCl}$, were compared with Eq. (13). As a result, in order to describe the kinetic diagram of the fatigue crack growth in 17G1S steel in air, the following formula is deduced

$$
\begin{aligned}
& d l / d N \approx 12 \cdot 10^{-9}\left(K_{I \max }^{4}-81\right) /\left(12996-K_{I \max }^{2}\right)^{-1} \\
& d l / d N \approx 5 \cdot 10^{-6}\left(K_{I \max }^{2}-25\right) /\left(12996-K_{I \max }^{2}\right)^{-1}
\end{aligned}
$$

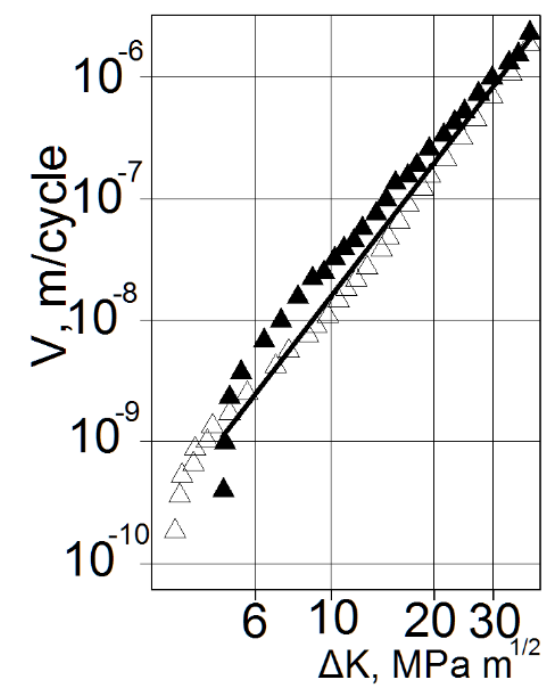

Figure 2. Kinetic diagram of $17 \mathrm{G} 1 \mathrm{~S}$ steel fatigue failure in air $(\Delta)$ and in $3 \%$ solution $\mathrm{NaCl} \mathrm{E}_{\text {кор }}$, at a frequency of $1 \mathrm{~Hz}(\boldsymbol{\Delta})$ and $\mathrm{R}=0.1[27,30]$.

Similarly, for the $3 \%$ solution $\mathrm{NaCl}_{\text {кор }}$, to depict the kinetic diagram of the corrosion-fatigue crack propagation in $17 \mathrm{G} 1 \mathrm{~S}$ steel, the following equation is obtained

$$
d l / d N \approx 5 \cdot 10^{-6}\left(K_{I \max }^{2}-25\right) /\left(12996-K_{I \max }^{2}\right)^{-1}
$$

\section{Pre-threshold Propagation of a Corrosion-Fatigue Crack.}

In the threshold site of the kinetic diagram of the corrosion-fatigue crack propagation ( $K_{f C}>K_{I} \rightarrow K_{s c c}$ ), the anode processes are more active as compared with mechanical destruction, that is $l_{a} \geq l_{m}$. Then, for this site, the corrosion-fatigue crack will propagate at the same velocity mainly. The kinetic diagram of the velocity of corrosion-fatigue crack growth (VCFCG) will have a plateau [19, 25-26, 30], see Figure 3 [27, 30]. This is explained by the fact $[19,24-29]$ that, due to the large time intervals $\Delta t$ of the incubation period of preparing an elemental jump of a crack, its peak grows blunt with the growth of CIF $K_{I}$, the concentration of stress decreases and, accordingly, $V$ stabilizes. In these sections of VCFCG diagrams (with an error to increase the durability reserve), we can assume that (the model part of the diagram in Figure 3 is represented by a dashed line) the corrosion-mechanical crack increases with the same speed $V_{c}$ to the intersection with the 
diagram of fatigue crack propagation at the coefficient value intensity of stress $K_{I \max }=K_{I i}$. Thus, the VCFCG kinetic diagram is described by the relations:

on the site $K_{s c c}<K_{I \max } \leq K_{I i}, V=V_{c}$;

on the site $K_{I i}<K_{I \max }<K_{f C}$,

$$
d l / d N=\beta_{1}(1-R)^{4}\left(K_{I \max }^{4}-K_{s c c \max }^{4}\right)\left(K_{f C}^{2}-K_{I \max }^{2}\right)^{-1}
$$

These ratios are applied to determine the residual life of thin-walled elements of vehicle structures (the period of sub-critical growth of corrosion-fatigue crack) under cyclic loads and corrosive influences.

\section{Determination of the Period of Subcritical Growth of a Corrosion-Fatigue Crack.}

The infinite plate is weakened by a rectilinear crack of the initial length $2 l_{0}$. It is cyclically loaded with tensile forces in distant points by continuous amplitude $\mathrm{p}$ efforts, which are perpendicular to the line of the crack location. When corrosive aggressive environment enters a crack cavity, the growth of the corrosion-fatigue crack is described by the Eq. (18) and the data in Figure 3. The challenge is to determine the number of load cycles of an element - a plate of thin-walled metal construction of a vehicle $\mathrm{N}=\mathrm{N}_{*}$. Achieving this number, a crack gains its critical size $1\left(\mathrm{~N}_{*}\right)=1_{*}$ and the knot breaks down. To solve this problem, the following mathematical model in Eq. (19) is written;

$$
\begin{aligned}
& V=V_{c}, K_{s c c}<K_{I \max } \leq K_{I i} ; \\
& d l / d N=\beta_{1}(1-R)^{4}\left(K_{I \max }^{4}-K_{s c c \max }^{4}\right)\left(K_{f C}^{2}-K_{I \max }^{2}\right)^{-1}, K_{I i}<K_{I \max }<K_{f C} ; \\
& N=0, l(0)=l_{0} ; N=N_{*}, l\left(N_{*}\right)=l_{*}, K_{I}\left(l_{*}\right)=K_{f C}
\end{aligned}
$$

For the given power scheme, the intensity of the stresses is determined by [5]:

$$
K_{I}=p \sqrt{\pi l}
$$

For example, if a thin-walled element (plate) is made of $17 \mathrm{G} 1 \mathrm{~S}$ steel, the loading value $\mathrm{p}=200 \mathrm{MPa}$ in the of $3 \% \mathrm{NaCl}$ solution with a flood potential $E=-2 B$ and $R=0.5$ (Figure 3), the ratios (18) are recorded.

$$
d l / d N=10^{-6}, 12<K_{I}<64 ; \frac{d l}{d N}=\frac{45 \cdot 10^{-11}\left(K_{\operatorname{Imax}}^{4}\right.}{12996-K_{\operatorname{Imax}}^{2}, 64<K_{I}<114}
$$




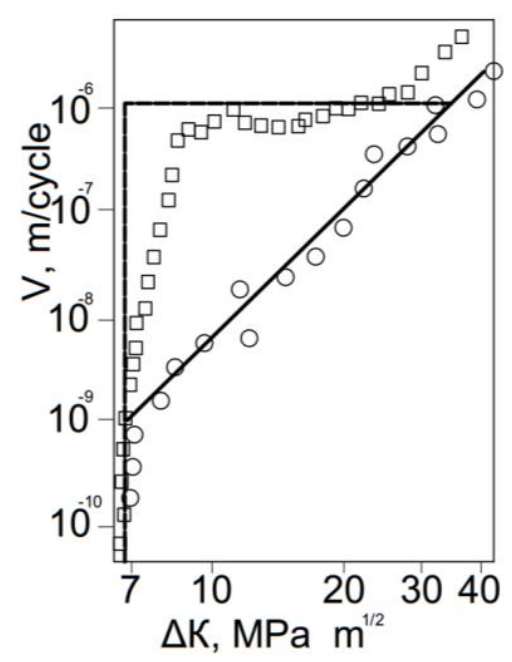

Figure 3. Kinetic diagram of $17 \mathrm{G} 1 \mathrm{~S}$ steel fatigue failure in air (०) and in $3 \%$ solution $\mathrm{NaClE}=-2 B(\square)$ at $R=0.5$ [27, 30]; dotted line - a model representation of the corrosive part of the diagram.

$\mathrm{N}=0,1(0)=1_{0} ; \mathrm{N}=\mathrm{N}_{*}, 1\left(\mathrm{~N}_{*}\right)=1_{*}, \mathrm{~K}_{\mathrm{I}}\left(\mathrm{l}_{*}\right)=114 \mathrm{MPa}^{1 / 2}$. To determine the residual life $\mathrm{N}=\mathrm{N}_{*}$ of a vehicle (plate) element, the ratio (21) is integrated with the given initial and final conditions. The resulting formula is;

$$
\begin{aligned}
& N_{*}=N_{1}+N_{2}, N_{l}=10^{6}\left(l_{1}-l_{0}\right) \\
& N_{2}=2 \cdot 10^{9} \int_{l_{1}}^{l_{*}}\left(158 \cdot 10^{8} l^{2}-20736\right)^{-1}\left(12996-13 \cdot 10^{4} l\right) d l
\end{aligned}
$$

The values $l_{1}, l_{*}$ in (22) are deduced from equations $K_{I}\left(l_{*}\right)=K_{f C}, K_{I}\left(l_{1}\right)=K_{I i}$. The resulting formulas are $l_{*}=0.103 \mu, l_{1}=0.033 m$. Substituting in Eq. (22), we obtain;

$$
\begin{aligned}
& N_{*}=\left(33 \cdot 10^{3}-10^{6} l_{0}+15510\right)\left(0,001<l_{0} \leq 0,033\right) \\
& N_{*}=1650\left(l_{0}^{-1}+10 \ln l_{0}+13,3\right)\left(0,033 \leq l_{0}<0,103\right)
\end{aligned}
$$

Based on (23), the graphical dependence of the residual life $N=N *$ of a thin-walled element (a plate) on the initial size of a crack (curve 1) is developed in Figure 4. The case of corrosive environment absence under the equivalent force load of a thin-walled element (curve 2), the dependence $N_{*} \sim l_{0}$ is developed as well. Thus, from Figure 4 , a decrease in a service life under the effect of corrosive environment is observed during a crack growth from $0.001 \mathrm{~m}$ to $0.033 \mathrm{~m}\left(l_{t h}<l<l_{1}\right)$. Then, the propagation of exclusively fatigue cracks occurs. This process is explained by the fact that at $l>l_{1}$, a velocity of crack propagation is large and the delayed corrosion processes do not have time to be realised. 


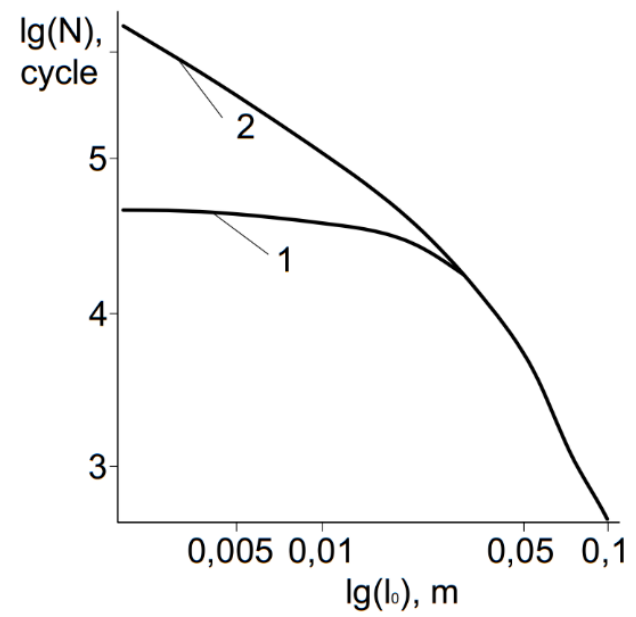

Figure 4. Dependence of residual life $N_{*}$ on the initial crack length $1_{0}$ : curve 1 - considering the environment, curve 2 - without considering the corrosion environment.

\section{CONCLUSION}

The analytical model of the description of delayed fracture for determining the residual life of thin-walled elements of vehicles metal structures under the action of cyclic loads and corrosive aggressive environments is substantiated. Based on the obtained solutions, the residual life of a steel plate (doped 17G1S steel) with a crack under the action of longterm cyclic tension loads in a $3 \% \mathrm{NaCl}$ solution is defined. The increase of the initial size of the rectilinear crack is proved to reduce significantly the residual durability of the structural element. The correctness of the developed mathematical model for determining the residual life of structural elements is confirmed by the experimental data known in the literature.

\section{REFERENCES}

[1] Schijve J. The significance of fatigue crack initiation for predictions of the fatigue limit of specimens and structures. International Journal of Fatigue 2014; 61: 3945.

[2] Dmytrakh IM, Smiyan OD, Syrotyuk AM, Bilyy OL. Relationship between fatigue crack growth behaviour and local hydrogen concentration near crack tip in pipeline steel. International Journal of Fatigue 2013; 50: 26-32.

[3] Bilotta G, Arzaghi M, Hénaff G, Benoit G, Moriconi C, Halm D. Hydrogen assisted fatigue crack growth in a precipitation-hardened martensitic stainless steel under gaseous hydrogen. Proc. ASME. 46049. 2014; 6B: Materials and Fabrication, V06BT06A014: PVP2014-28381/doi: 10.1115/PVP2014-28381.

[4] Andreikiv OE, Lysyk AR, Shtayura NS, Babii AV. Evaluation of the residual service life of thin-walled structural elements with short corrosion-fatigue cracks. Materials Science 2017; 4: 514-521.

[5] Andreikiv OE, Dolinska IYa, Lysyk AR, Sas NB. The calculation model of propagation of corrosion-mechanical cracks at high temperatures. Materials Science 2017; 1: 34-40. 
[6] Popovich PV, Barna RA. Influence of operating media on the fatigue fracture of steels for elements of agricultural machines. Materials Science 2014; 50, 3: 377380.

[7] Maruschak PO, Sorochak AP, Konovalenko IV. Stereoscopic analysis of the stretch zone of a steel specimen cut out of a railway axle and tested for static fracture toughness. Journal of Failure Analysis and Prevention 2015: 15 (3); 436440.

[8] Yasniy O, Lapusta Y, Pyndus Y, Sorochak A, Yasniy V. Assessment of lifetime of railway axle. International Journal of Fatigue 2013; 50: 40 - 46.

[9] Dmytrakh IM, Syrotyuk AM, Leshchak RL. Methods for the investigation the specific features of interaction of deformed metal surfaces of pipelines with hydrogen-containing media. Nauk. Visn. Ivano-Frank. Nats. Univ. Nafty Gazu 2013; 35(2); 144-154.

[10] Panasyuk, VV, Ivanyts'kyi YL, Hembara OV, Boiko VM. Influence of the stressstrain state on the distribution of hydrogen concentration in the process zone. Materials Science 2014; 50(3); 315-323.

[11] Chamat A, Aden-Ali S, Gilgert J, Petitc E. and all. Crack behaviour in zinc coating and at the interface zinc-hot galvanised TRIP steel 800. Engineering Fracture Mechanics 2013; 114: 15-25.

[12] Bilotta G, Arzaghi M, Hénaff G, Benoit G, Halm D. Hydrogen induced intergranular failure in armco iron under fatigue crack propagation. ASME. Pressure Vessels and Piping Conference 2016; 6B: V06BT06A026; PVP201663338.

[13] Liu ZY, Wang XZ, Du CW, Li JK, Li XG, Liu ZY, Wang XZ, Du CW, Li JK, Li $\mathrm{XG}$. Effect of hydrogen-induced plasticity on the stress corrosion cracking of X70 pipeline steel in simulated soil environments. Materials Science and Engineering A 2016; 658: 348-354.

[14] Moustabchir H, Arbaoui J, Zitouni A, Hariri S., Dmytrakh, I. Numerical analysis of stress intensity factor and T-stress in pipeline of steel P264GH submitted to loading conditions. Journal of Theoretical and Applied Mechanics 2015: 53 (3); 665-672.

[15] Andreikiv OE, Dobrovol's'ka LN, Yavors'ka NV. Computational model of crack propagation in bimetallic materials for high concentrations of hydrogen and high temperatures. Materials Science 2015; 51, 1: 76-8.

[16] Popovych P, Shevchuk O, Dzyura V, Poberezhna L, Dozorskyy V, Hrytsanchuk A. Assessment of the influence of corrosive aggressive cargo transportation on vehicle reliability. International Journal of Engineering Research in Africa 2018; 38: 17-25.

[17] Popovych PV, Lyashuk OL, Murovanyi IS, Dzyura VO, Shevchuk OS, Myndyuk VD. The service life evaluation of fertilizer spreaders undercarriages. INMATEHAgricultural Engineering 2016; 50(3): 39-46.

[18] Popovych PV, Lyashuk OL, Shevchuk OS, Tson OP, Bortnyk IM, Poberezhna LYa. Influence of organic operation environment on corrosion properties of metal structure materials of vehicles. INMATEH-Agricultural Engineering 2017; 52(2): 113-119.

[19] Andreikiv OE, Kukhar VZ, Dolinska IYa. Propagation of high-temperature creep cracks in metals subjected to neutron irradiation (a survey). Materials Science 2015; 51, 3: 299-310. 
[20] Andreikiv OE, Yavors'ka NV, Kukhar VZ. Mathematical models for estimating the residual life of plates with systems of cracks under the action of long-term static loads, high temperatures, and hydrogen. Journal of Mathematical Sciences 2016; 212, 2: 121-130.

[21] Dmytrakh, IM, Leshchak, RL, Syrotyuk AM, Barna RA. Effect of hydrogen concentration on fatigue crack growth behaviour in pipeline steel. International Journal of Hydrogen Energy 2017; 42, 9: 6401-6408.

[22] Turnbull A. Perspectives on hydrogen uptake, diffusion and trapping. International Journal of Hydrogen Energy 2015; 40(47): 16961-16970.

[23] Capelle G, Dmytrakh J, Azari I, Pluvinage Z. Evaluation of electrochemical hydrogen absorption in welded pipe with steel API X52. International Journal of Hydrogen Energy 2013; 38 (33): 14356-14363.

[24] Kosarevych RY, Svirs'Ka LM, Rusyn BP, Nykyforchyn HM. Computer analysis of characteristic elements of fractographic images. Materials Science 2013: 48(4); 474-481.

[25] Djukic, MB, Sijacki Zeravcic, V, Bakic, Sedmak GM, Rajicic B. Hydrogen damage of steels: A case study and hydrogen embrittlement model. Engineering Failure Analysis 2015: 2 (58);485-498.

[26] Syrotyuk AM. Determination of the period of formation of a corrosion-fatigue crack in pipelines of power-generating equipment. Visn. Dal' Skhidnoukr. Nats. Univ 2013: 198(9); 185-190.

[27] Qian X. Failure assessment diagrams for circular hollow section X- and K-joints. International Journal of Pressure Vessels and Piping 2013: 104; 43-56.

[28] Lu K, Meshii T. Three-dimensional T-stresses for three-point-bend specimens with large thickness variation. Engineering Fracture Mechanics 2014: 116; 197203.

[29] Dmytrakh IM, Syrotyuk AM, Lutyts'kyi OL. Comparative investigations of the fracture processes in pipes under the pressure of gaseous hydrogen and pure methane. Rozv. Rozrob. Naft. Gaz. Rodov 2013: 49(4); 34-44.

[30] Andreikiv AY, Darchuk AI. Fatigue failure and durability of structures. Naukova Dumka; 1992.

[31] Andreikiv OY, Kit MB. Determination of residual durability of thin-walled elements of structures at two-axis load. Physical-chemical mechanics of materials 2006: 1; 11-16.

[32] Andreikiv OY, Kit MB. Determination of the period before the critical growth of cracks in the elements of structures at their two frequency loadю. Mechanical Engineering 2006: 2; 3-9. 